\title{
Pentáculo Ambiental: instrumento para verificação das atitudes
}

\section{ambientais de estudantes de Ibirubá/RS}

\section{Environmental pentacle: tool for verification of environmental attitudes of students} Ibirubá / RS

\author{
${ }^{1}$ Cadidja Coutinho, ${ }^{2}$ Raquel Ruppenthal, ${ }^{2}$ Martha Bohrer Adaime e ${ }^{1}$ Marcos Vinicios \\ Machado Machado \\ ${ }^{1}$ Universidade Regional Integrada do Alto Uruguai e Missões - URI Campus Santiago,Brasil \\ cadidjabio@gmail.com;marcos8113@gmail.com \\ ${ }^{2}$ Universidade Federal de Santa Maria, Santa Maria, Brasil \\ rkruppenthal@gmail.com; martha@ufsm.br
}

\begin{abstract}
Resumo
Atualmente, inúmeras iniciativas buscam reestabelecer o lugar do homem na natureza e suas relações com ela, sensibilizando para a implementação de uma cultura ecológica. Neste contexto, a fim de averiguar os conhecimentos sobre sustentabilidade e demonstrar a importância da reflexão sobre o pensar ambiental, elaborouse um instrumento de verificação das atitudes ambientais, o "Pentáculo Ambiental". O modelo está baseado na política dos $5 R$ 's, e busca incitar as estratégias para o desenvolvimento sustentável, de forma individual e coletiva. Além disso, o presente trabalho propôs-se a investigar a aplicabilidade desta ferramenta pedagógica na identificação do estilo de vida dos estudantes do ensino fundamental de uma escola pública no município de Ibirubá/RS. A partir da análise dos dados foi possível identificar as principais concepções dos estudantes sobre atitudes ecosustentáveis, positivamente apresentadas nos itens do $R$ - Reduzir, e os aspectos que merecem apreensão, como o $R$ - Reciclar e o $R$-Recusar. Através da aplicação do Pentáculo Ambiental, identificou-se ainda, ser necessário incentivar práticas de aproveitamento de materiais diversos como mecanismo de disseminação ecosustentável; explorar estratégias de equidade social e ecológica na produção de bens e serviços através da gestão ambiental; e fomentar a prática de Educação Ambiental na formação de valores em prol do meio ambiente.
\end{abstract}

Palavras-chave: Desenvolvimento sustentável; Educação Ambiental; Política dos 5 R's.

\begin{abstract}
Currently, many initiatives look for re-establishing the man's place in nature and its relationships with it, raising awareness for the implementation of an ecological culture. In this context, in order to ascertain the knowledge about sustainability and demonstrate the importance of reflection on the environmental thinking, a tool for verification of environmental behaviors was enacted, known as the "Environmental Pentacle". The model is based on the $5 R$ 's policy and pursues to encourage the strategies for sustainable development individually and collectively. In addition, this study aimed to investigate the applicability of this pedagogical tool in identifying the lifestyle of middle school students in a public school in the city of Ibirubá/RS. From the data analysis, it was possible to identify the main conceptions of the students on ecologically sustainable behaviors positively presented in the R-Reduce items and in the aspects that should be collected, like the R-Recycle and R-Refuse. Through the application of the Environmental Pentacle, it was possible to identify the necessity to encourage practices in the utilization of many materials such as ecologically sustainable dissemination mechanism, exploration of the social and ecological equity strategies in the production of goods and services through environmental management, and promotion of the Environmental Education practice in the development of values in favor of the environment.
\end{abstract}

Keywords: Sustainable development; Environmental education; Politics of the 5 R's. Recebido: 07/06/2016 Aceito: 08/08/2016 


\section{Introdução}

Durante as últimas décadas diferentes iniciativas nacionais e internacionais tem enfatizado que a educação é um imperativo para que a sociedade se torne mais sustentável (RAMOS et al., 2015). No entanto, existem ainda muitos desafios para integrar o desenvolvimento sustentável (DS) e muitas oportunidades para investigação do tema.

Considerando que a ideia de avanço econômico, social e ecológico deve se tornar uma base conceitual para o ensino, Nasibulina (2015) afirma que, os requisitos necessários para o DS da sociedade estão alicerçados em um sistema educacional, onde a formação da personalidade é definida pela qualidade de pensamento; pela capacidade de modelar e construir o futuro; pelos valores morais, atitudinais e comportamentais.

Para uma abordagem socioeducativa se tornar pragmática, um sistema social deve ser arquitetado via educação planetária e na idealização de um sujeito ecológico (CARVALHO, 2012). Por outro lado, uma perspectiva social eficaz é aquela que envolve uma abordagem específica sobre o meio ambiente e a educação (POSTUICÃ, 2013; COSTEL, 2015).

Neste contexto, indaga-se como tem se dado o ensino para a sustentabilidade? Como tornar o discente um leitor crítico das questões ambientais? Ou mesmo, que reflexões são necessárias para despertar atitudes ecologicamente responsáveis nos estudantes?

Segundo Smaneoto e colaboradores (2012, p. 927) "a produção sustentável emerge como novo objeto científico interdisciplinar e a educação como um instrumento para a construção da racionalidade ambiental". Promover e apoiar ativamente a conduta ambiental exige a pesquisa sobre fontes de comportamento pró-sustentabilidade, a socialização de competências e valores democráticos e o desenvolvimento de um sentimento pessoal de responsabilidade individual e coletiva (CHAWLA e CUSHING, 2007).

De acordo com a fundadora do termo Gro Brundtland (1987 apud DA SILVA e BASTOS, 2007, p. 02) no relatório intitulado Our Common Future, o DS é concebido como "o desenvolvimento que satisfaz as necessidades presentes, sem comprometer a capacidade das gerações futuras de suprir suas próprias necessidades".

O ensino de questões para o DS pode ser organizado usando várias estratégias educacionais que integram, em maior ou menor grau, a complexidade do conhecimento do estudante envolvido e a relação entre ciência e sociedade (SIMONNEAUX, 2012). Nesse sentido, é importante a formação de cidadãos que não percebam simplesmente a importância do diálogo intercultural e o respeito à diversidade, mas também que entendam a necessidade de mudanças de compreensão de que o ecossistema é o meio para sustentar ou proporcionar a subsistência (NASIBULINA, 2015). A fim de que se consiga essa mudança de perspectiva, é importante reco- nhecer o que os estudantes pensam e sabem sobre o DS.

Dessa forma, o presente trabalho visa apresentar um modelo de verificação de atitudes ambientais, fundamentado pela política dos 5R's (GOVERNO..., [2016]). Além disso, investigar a sua aplicabilidade na identificação do estilo de vida dos estudantes e a reflexão sobre a importância do pensar ambiental a fim de propor estratégias para o desenvolvimento sustentável, de forma individual e coletiva.

\section{Referencial teórico}

A construção de um projeto transformador para sociedade, voltado à formação de indivíduos críticos e responsáveis ambientalmente, sinaliza atributos do desenvolvimento sustentável (DS).

Pensar o ambiental, hoje, significa pensar de forma prospectiva e complexa, introduzir novas variáveis nas formas de conceber o mundo globalizado, a natureza, a sociedade, o conhecimento e especialmente as modalidades de relação entre os seres humanos, a fim de agir de forma solidária e fraterna, na procura de um novo modelo de desenvolvimento (MEDINA, 2011, p.12).

Questões sociocientíficas dentro da perspectiva da sustentabilidade tornaram-se uma exigência institucional em muitos países. Além disso, assume muitas formas de integração ao ensino desta temática (SIMONNEAUX, 2012). Porém, na educação para o ambiente, ou educação ambiental, o intuito não é identificar uma metodologia ideal, mas indicar perspectivas para fomentar a inventividade e a criatividade na educação e na investigação ambiental (BERRYMAN e SAUVÉ, 2016).

Neste contexto, subsidiar ações para a sustentabilidade depende da articulação entre a educação e a problematização da realidade de vida (TORRES; FERRARI e MAESTRELLI, 2014), garantindo habilidades para uma nova percepção do meio ambiente.

A educação para uma vida sustentável estimula tanto o
entendimento intelectual da ecologia como cria víncu-
los emocionais com a natureza, Por isso, ela tem muito
mais probabilidade de fazer com que as nossas crianças
e os jovens se tornem cidadãos responsáveis e realmente
preocupados com a sustentabilidade da vida, que sejam
capazes de desenvolver uma paixão pela aplicação dos
seus conhecimentos ecológicos à reformulação das nossas
tecnologias e instituições sociais, de maneira a preencher
a lacuna existente entre a prática humana e os sistemas da
natureza ecologicamente sustentáveis (CAPRA, 2006, p. 15).

A educação para o DS, ou educação ambiental, deve favorecer um retorno à harmonia com a natureza, a fim de restabelecer o equilíbrio do ecossistema e permitir o florescimento de todo o potencial humano, sem compro- 
meter os ecossistemas para outras espécies. O objetivo da educação ambiental deve ser o de trazer uma mudança radical na relação do ser humano com o meio, e dar ênfase à relação de posse ou domínio, substituindo a visão antropocêntrica para a biocêntrica (KOPNINA, 2012).

Para este fim, a utilização de uma nova linguagem para gerenciar a natureza, como a política dos 5R's (Reduzir, Reutilizar, Reciclar, Recusar e Repensar), pode representar um incremento ao futuro sustentável. Segundo o Ministério do Meio Ambiente (GOVERNO..., [2016]) “a política dos 5R's faz parte de um processo educativo que tem por objetivo uma mudança de hábitos no cotidiano dos cidadãos, deve priorizar a redução do consumo e o reaproveitamento dos materiais em relação à sua própria reciclagem". Porém, a mudança de hábitos só é possível ao se reconhecer costumes que podem ser melhorados, ou seja, identificar as atitudes individuais e coletivas, pós e contra o meio ambiente.

Dessa forma, como princípio para redução adota-se a diminuição do consumo desenfreado, optando por produtos de maior durabilidade, e observando características como a marca, validade e/ou tamanho. Quanto ao processo de reutilização considera-se o aproveitamento do material de forma a aumentar a sua vida útil e ao mesmo tempo evitar a extração de novas matérias-primas para sua confecção. Para a reciclagem institui-se o planejamento para separação do lixo e destinação correta, ou seja, "o reaproveitamento de materiais beneficiados como matéria-prima para um novo produto" (SANTOS, 2015, p. 17). O processo de negação ou recusa designa a escolha de produtos que tenham compromisso com a natureza. Já para repensar é preciso avaliar os possíveis benefícios e danos que o bem ou serviço pode gerar ao meio ambiente.

Diante disso, considera-se que a realização de ações que envolvem os atributos dos 5R's pode produzir consequências positivas e uma significativa redução dos impactos ambientais e sociais. E como afirma Lopes e Moura (2015, p. 137) "ao adotar tais atitudes os cidadãos estariam considerando toda a coletividade, visto que a partir de ações individuais proporcionariam à sociedade um mundo mais sustentável".

\section{Metodologia}

\subsection{Desenvolvendo um instrumento de}

\section{verificação dos valores ecológicos.}

A fim de investigar os conhecimentos acerca da sustentabilidade, elaborou-se um instrumento de verificação das atitudes ambientais, baseado na política dos 5R's. O questionário foi confeccionado a partir de uma adaptação do modelo de coleta de dados denominado Pentáculo do Bem-Estar (NAHAS, 2013). Esta é uma análise do estilo de vida, que pode ser utilizada

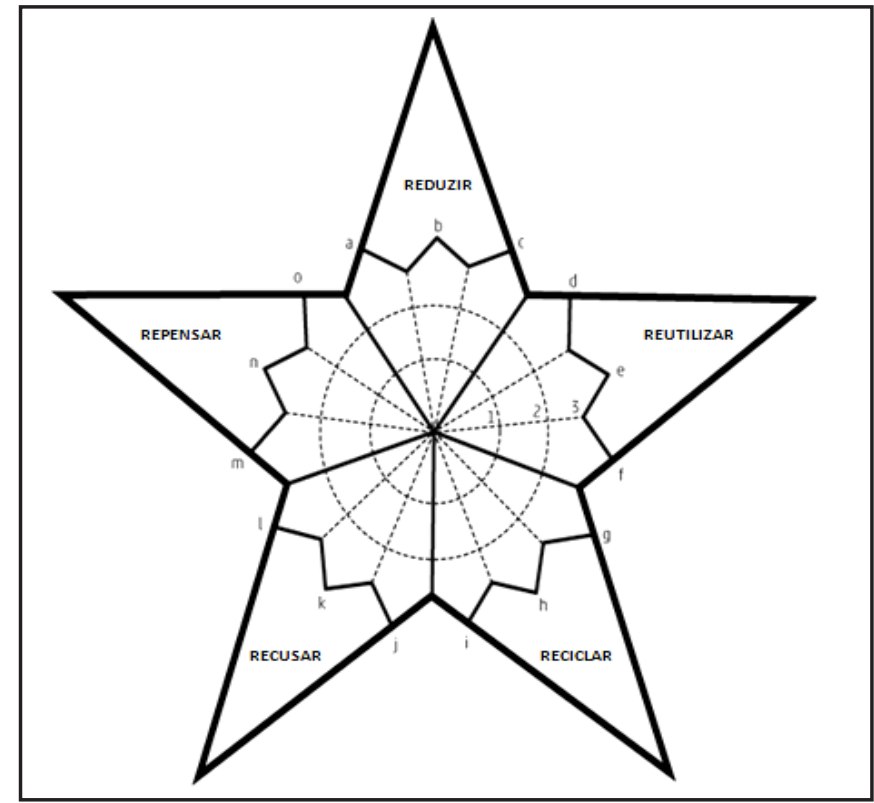

Figura 01 - Modelo de Pentáculo Ambiental utilizado para coleta de dados. Adaptado de NAHAS, M. V. (2013).

como base para mediações individuais e/ou coletivas, objetivando mudanças comportamentais dos indivíduos (VICENTE et al., 2009).

Dessa forma, o modelo apresentado foi intitulado "Pentáculo Ambiental" e está organizado em forma de pentagrama ou de estrela, sendo cada um dos eixos representa um dos R (Reduzir, Reutilizar, Reciclar, Recusar e Repensar), conforme ilustra a Figura 01.

Para cada $\mathrm{R}$ existem três apontamentos associados ao tema (Quadro 01), e para respondê-los é necessário utilizar a escala de 0 a 3 , sendo 0 - absolutamente não faz parte do meu estilo de vida; 1 - às vezes corresponde ao meu comportamento; 2 - quase sempre verdadeiro no meu comportamento; 3 - a afirmação é sempre verdadeira no meu dia-a-dia, faz parte do meu estilo de vida. Para fazer a escolha da escala correspondente, deve-se colorir as regiões indicadas (para 0 - não colorir; para 1 - colorir a marcação do primeiro círculo; para 2 - colorir a marcação do primeiro e segundo círculo; para 3 - colorir a marcação para os três círculos).

As respostas apresentadas podem ser analisadas de forma coletiva para o grupo de aplicação, explorando as escalas de maior e de menor preferência e/ou costume para cada um dos 5R's, discutindo qual dos R's é mais aplicado no cotidiano, qual o menos observado por eles, bem como os motivos; média entre as respostas e as suas correlações estatísticas. Além disso, o instrumento pode ser utilizado para constatações de concepções individuais, seguindo o nivelamento para o somatório das respostas na escala de 0 a 3 (Tabela 1 ). 
Quadro 01 - Questões utilizadas para os 5R's.

\begin{tabular}{|c|c|c|}
\hline & & QUESTÃO UTILIZADA \\
\hline \multirow{3}{*}{ 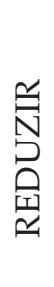 } & a. & Planejo bem as compras para não haver desperdício. \\
\hline & b. & $\begin{array}{l}\text { Escolho produtos com menos embalagens, embalagens econômicas, priorizando as retornáveis } \\
\text { e/ou refil (conteúdo descartável de alguns produtos, que pode ser substituído: cargas de caneta } \\
\text { esferográfica, batons, repelentes etc.). }\end{array}$ \\
\hline & c. & Edito (corrijo) textos na tela do computador para evitar a impressão. \\
\hline \multirow{3}{*}{ 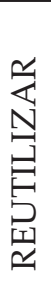 } & d. & $\begin{array}{l}\text { Faço impressão frente/verso das folhas e uso o outro lado das folhas de papel já utilizadas para } \\
\text { rascunhos e blocos de anotação. }\end{array}$ \\
\hline & e. & Faço a doação de objetos que possam servir a outras pessoas. \\
\hline & f. & Reutilizo embalagens de papel, vidro, plástico, metal, isopor, etc. \\
\hline \multirow{3}{*}{ 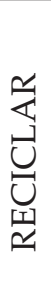 } & g. & Faço a utilização de água da chuva para limpezas em geral. \\
\hline & h. & Faço a separação do lixo para facilitar a coleta seletiva. \\
\hline & i. & $\begin{array}{c}\text { Reaproveito o lixo orgânico (cascas de frutas, restos de alimentos, etc.) para produção adubo } \\
\text { de plantas, através da compostagem. }\end{array}$ \\
\hline \multirow{3}{*}{ 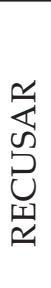 } & $\mathrm{j}$. & Recuso folhetos de propaganda que não forem de meu interesse. \\
\hline & $\mathrm{k}$. & $\begin{array}{c}\text { Evito empacotamentos desnecessários, levando ao supermercado ou feira a própria bolsa de } \\
\text { compras. }\end{array}$ \\
\hline & 1. & Rejeito produtos que não possuam identificação/selo/comprovação ou compromisso ecológico. \\
\hline \multirow{3}{*}{ 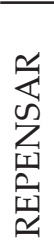 } & m. & Pergunto-me sobre a necessidade do produto que estou adquirido antes do consumo. \\
\hline & n. & Reflito sobre meus hábitos de consumo e as consequências para meio ambiente. \\
\hline & o. & Repenso as minhas práticas de descarte dos resíduos. \\
\hline
\end{tabular}

Tabela 01 - Nivelamento individual para o somatório das respostas na escala de 0 a 3.

\begin{tabular}{c|c|c}
\hline PONTUAÇÃO & INDICATIVO & DESCRIÇÃO \\
\hline Até 15 pontos & NEGATIVO & $\begin{array}{c}\text { Suas atitudes não seguem os princípios da } \\
\text { sustentabilidade. }\end{array}$ \\
\hline 16 a 30 pontos & INTERMEDIÁRIO & $\begin{array}{c}\text { Suas atitudes apresentam uma tendência ao } \\
\text { indicador da sustentabilidade. }\end{array}$ \\
\hline 31 a 45 pontos & POSITIVO & Suas atitudes são ecosustentáveis. \\
\hline
\end{tabular}




\section{Testando a viabilidade do modelo "Pentáculo}

\section{Ambiental".}

Para examinar se o instrumento elaborado atinge seu objetivo, ele foi aplicado em turmas de estudantes do Ensino Fundamental (5o ao $9^{\circ}$ ano) da Escola Estadual de Ensino Fundamental Ibirubá, totalizando 125 estudantes. A escolha do local de intervenção se dá pela oportunidade de aproximação do meio acadêmico ao espaço escolar, principalmente, por se tratar de uma escola que durante o presente ano letivo está desenvolvendo um projeto interdisciplinar sobre Educação Ambiental e Sustentabilidade com alunos de $5^{\circ}$ ao $9^{\circ}$ ano do Ensino Fundamental. Além disso, uma das pesquisadoras atua como docente no local, o que facilita as interfaces entre a universidade e a instituição escolar.

Após a leitura da afirmativa, os estudantes foram instruídos a colorir o item conforme sua atitude ambiental. Utilizou-se como dados para análise a resposta dada para cada afirmação do $R$ em questão, através da pintura da escala de 0 a 3 . Essa resposta poderia ser "não, às vezes, quase sempre ou sempre". Ressalta-se que os estudantes já tinham o conhecimento teórico relativo à sustentabilidade. A partir do preenchimento do "Pentáculo Ambiental" utilizou-se uma análise bidimensional, com medidas de associação entre variáveis (MORETTIN e BUSSAB, 2010), e o teste qui-quadrado, a fim de encontrar um valor para a dispersão entre duas variáveis e avaliar o nível de associação existente entre as mesmas (BARBETTA, 2014).

Esta pesquisa foi submetida à apreciação pelo Comitê de Ética em Pesquisa da Universidade Regional Integrada do Alto Uruguai e Missões - Campus Santiago e executada após a aprovação conforme a Resolução 466/12 do Conselho Nacional de Saúde.

\section{Resultados}

A análise dos resultados mostra que 125 estudantes participaram da atividade, sendo 67 do sexo masculino e 58 do sexo feminino, idades entre 10 e 17 anos, todos cursando o Ensino Fundamental da escola.

$\mathrm{O}$ trabalho realizado teve como intuito identificar as principais concepções dos estudantes sobre atitudes ecosustentáveis. Como já mencionado, a ferramenta pedagógica escolhida para fazer essa sondagem foi o "Pentáculo Ambiental". A partir dessa foi possível observar os seguintes resultados quanto ao grupo como um todo (Figura 02).

Com base na análise dos resultados apresentados no gráfico, podemos ressaltar alguns pontos positivos. Por exemplo, na temática Reduzir, o tópico C (Edito (corrijo) textos na tela do computador para evitar a impressão), a maioria respondeu "sempre" para a afirmação, ou seja, uma prática viável e necessária na era digital, evitando a impressão desnecessária de documentos e consequentemente, o uso abusivo do papel. Na temática Reutilizar, o item E (Faço a doação de objetos que possam servir a outras pessoas), a maioria apontou como resposta "quase sempre e/ou sempre", mostrando o potencial dos estudantes à solidariedade.

Entretanto, para a temática Reciclar, as afirmações G (Faço a utilização de água da chuva para limpezas em geral) e I (Reaproveito o lixo orgânico (cascas de frutas, restos de alimentos, etc.) para produção adubo de plantas, através da compostagem), a escala " 0 - absolutamente não faz parte do meu estilo de vida" representou a maioria das respostas. Isso demonstra a necessidade de incentivo aos mecanismos de reaproveitamento da água e de implementação das políticas de racionamento contra o desperdício. Também é necessário considerar a importância da compostagem, principalmente nas áreas urbanas, como a escolhida para a realização do presente trabalho, como estratégia para aproveitamento dos resíduos orgânicos produzidos nas residências, evitando o acúmulo e destino à coleta seletiva municipal, além de viabilizar o plantio de pequenas hortas e/ou jardins vertical, estimulando a alimentação saudável e o menor uso de fertilizantes químicos artificiais. Itens como esses, são tendências emergentes em grandes centros urbanos internacionais como Londres, Cingapura, Frankfurt ou Tóquio, e no território nacional, como em São Paulo, Rio de Janeiro e Brasília.

Além disso, na temática Recusar, chama atenção o número significativo de respostas negativas (escala 0) para o item L (Rejeito produtos que não possuam identificação/selo/comprovação ou compromisso ecológico), o que evidencia o desconhecimento sobre as propostas de gestão ambiental e sobre a importância da aquisição de "produtos verdes", oriundos de empresas que seguem os critérios da legislação ambiental.

Figura 02 - Análise das respostas apresentadas pela resolução do Pentáculo Ambiental.

( 0 - não faz parte do meu estilo de vida; 1 - às vezes faz parte do meu estilo de vida; 2 - quase sempre faz parte do meu estilo de vida; 3 - sempre faz parte do meu estilo de vida).

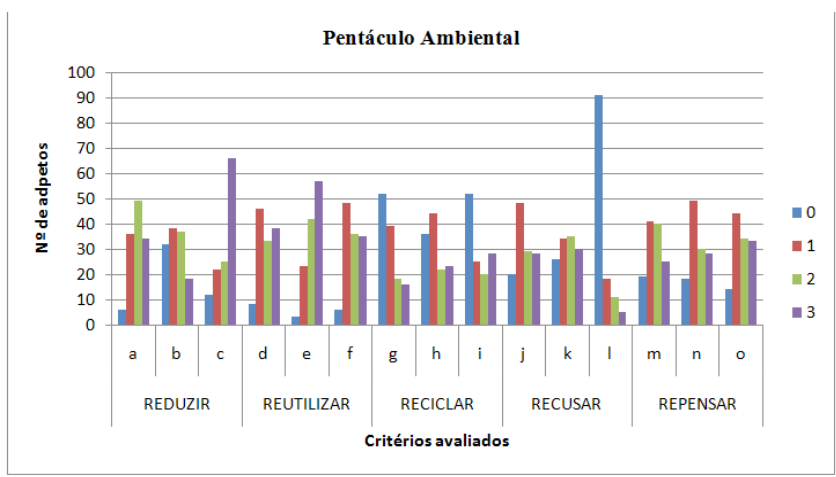

Fonte: Dados da pesquisa. 
Ao observar cada $\mathrm{R}$ individualmente (com os três apontamentos que o compõem) é possível assinalar que as escalas de menor e de maior preferência foram, respectivamente, 0 e 3 para Reduzir; 0 e 3 para Reutilizar; 2 e 0 para Reciclar; 3 e 0 para Recusar; e 0 e 2 para Repensar (Figura 03). A partir desses dados é possível inferir que as ações em prol da redução e da reutilização fazem parte do estilo de vida da maioria dos participantes; que a reciclagem e a recusa não fazem parte do dia-a-dia da maioria dos entrevistados; e que o estímulo a pensar sobre as atitudes ambientais é quase sempre presente nas ações dos estudantes amostrados.

De modo geral, as médias das respostas para cada nível da escala de 0 a 3 apresentaram pequenas oscilações (nível 0 - 21\%; nível 1 -29,56\%; nível 2 -24,61\%; e para nível $3-24,83 \%$ ), com maior tendência nas respostas para o quesito " 1 - às vezes". Isso pode indicar o desinteresse pelas questões ecológicas na faixa etária na qual se encontra o grupo da intervenção, ou mesmo, a falta de incentivo para prática rotineira de atitudes ambientais em casa e/ou na escola.

Analisando individualmente os Pentáculos, conforme o somatório da pontuação (escala de 0 a 3) é possível observar que $09(7,2 \%)$ participantes da atividade apresentaram o nível NEGATIVO; 108 (86,4\%) o nível INTERMEDIÁRIO; e $08(6,4 \%)$ o nível POSITIVO para os critérios analisados. Pontuação essa, que pode ser obervada na amostra de Pentáculos preenchidos pelos estudantes que participaram da atividade, conforme Figura 04.

A análise permite observar ainda, as relações estatísticas entre as variáveis dos cincos eixos do Pentáculo. Existem correlações significativas entre os apontamentos
A e I; D e F; D e O; E G; F e O; I e L; J e N; K e M, conforme os dados apontados pelo teste de qui-quadrado $(\mathrm{p}=0,000000)$. O que pode indicar a necessidade de interligação dos apontamentos escolhidos para cada $\mathrm{R}$, e que ao atingir a totalidade das ações, conforme a política dos $5 R^{\prime}$ s, possibilita-se melhores condições para o desenvolvimento sustentável.

Da mesma forma, as relações dentro das variáveis de cada R (frequências esperadas versus observadas), indicam significância em três dos $5 R^{\prime}$ s - Reduzir ( $p$ $=0,000000)$; Reutilizar ( $p=0,047630)$; e Recusar ( $p=$ 0,000000 ), de modo que existe uma associação entre os grupos de apontamento (as variáveis são dependentes), ou seja, para melhorar o R em questão, deve-se implementar atividades que modifiquem os hábitos referentes aquele R. Nesta perspectiva, para Reduzir é necessário planejamento, boas escolhas e diminuição dos desperdícios; para Reutilizar torna-se essencial aproveitar materiais para uma "segunda função", ou mesmo, doar a quem possa dar seguindo a sua função principal; e para Recusar é fundamental buscar novas formas para a publicidade/propaganda e para a alocação e o transporte de produtos, seguindo as indicações da legislação ambiental.

$\mathrm{Na}$ análise individual de cada afirmação (A até O), os resultados mostram que as frequências esperadas versus observadas são significativas para os apontamentos $\mathrm{A}(\mathrm{p}$ $=0,000006), B(p=0,047446), C(p=0,000000)$, itens componentes do primeiro $R$ - Reduzir; $D(p=0,000802), E$ ( $p$ $=0,000000), F(p=0,000140)$, correspondentes ao segundo $\mathrm{R}$ - Reutilizar; $\mathrm{G}(\mathrm{p}=0,000000), \mathrm{H}(\mathrm{p}=0,024541), \mathrm{I}(\mathrm{p}=$ $0,000000)$, parte integrante do terceiro $\mathrm{R}$ - Reciclar; e L $(p=0,000000)$ do $R$ - Recusar. Esses dados podem estar

Figura 03. Análise individual dos 5R's do Pentáculo Ambiental para a preferência de respostas na escala de 0 a 3. ( 0 - não faz parte do meu estilo de vida; 1 - às vezes faz parte do meu estilo de vida; 2 - quase sempre faz parte do meu estilo de vida; 3 - sempre faz parte do meu estilo de vida)

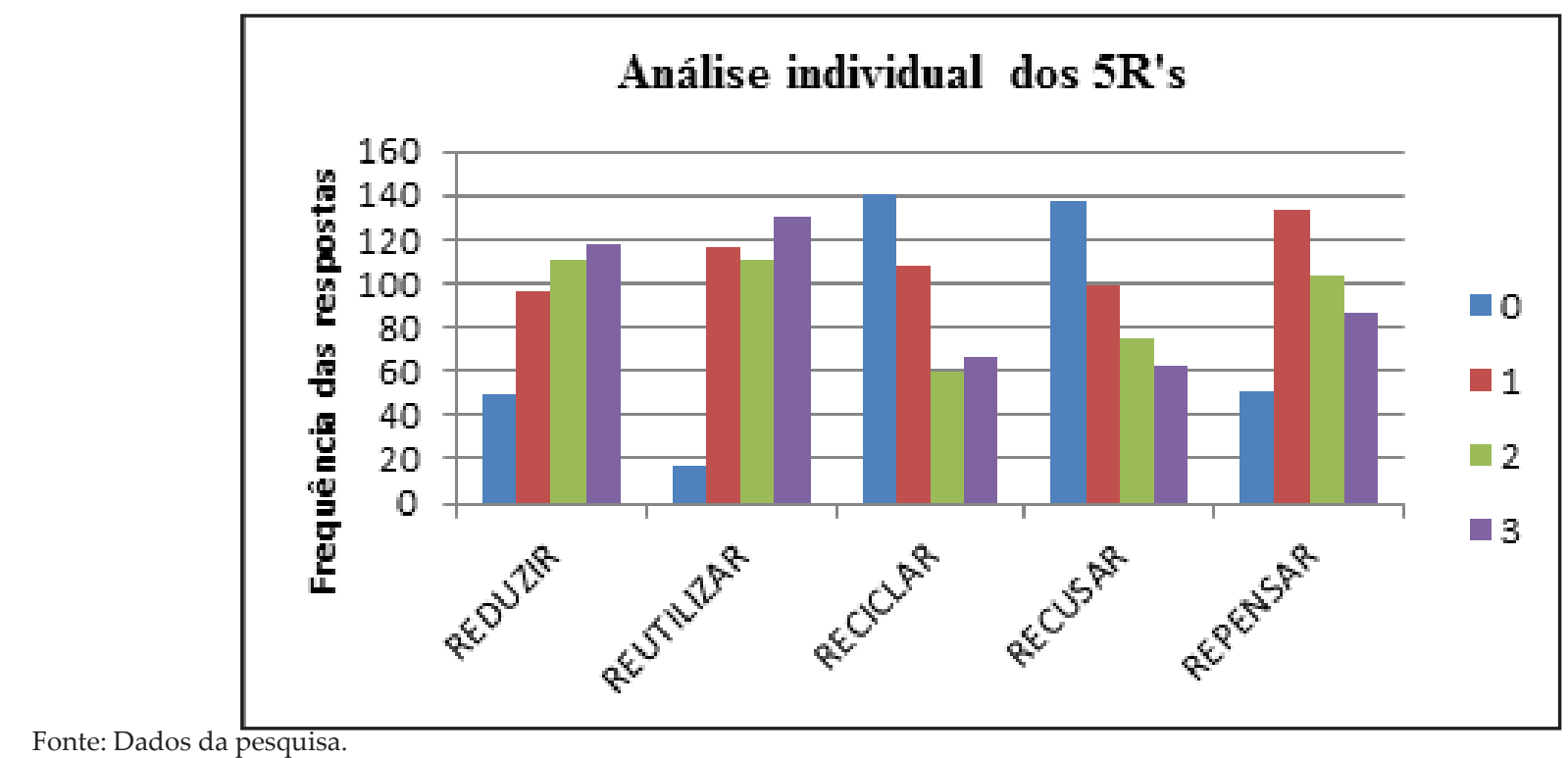




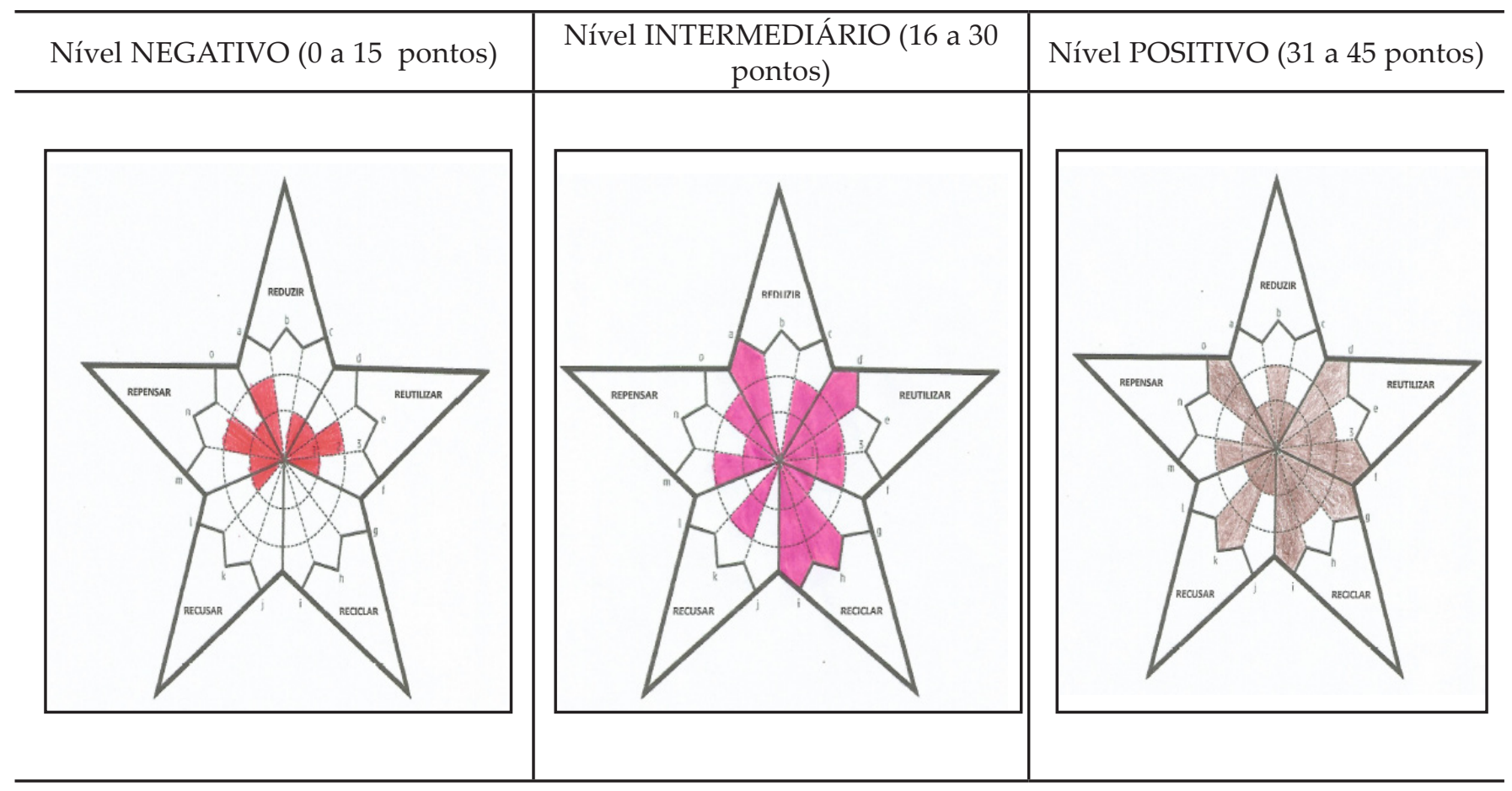

Figura 04. Pentáculo preenchidos pelos estudantes, representando os três níveis de avaliação individual das atitudes ambientais.

Fonte: Dados da pesquisa.

associados à facilidade de compreensão da afirmação correspondente e à aproximação da mesma com o cotidiano e com a realidade do participante (por exemplo, os R's - Reduzir, Reutilizar e Reciclar que estão rotineiramente presentes nas atividades letivas ou na mídia), ou à justaposição conceitual entre os significados de cada $\mathrm{R}$, principalmente quanto ao $\mathrm{R}$ - Reutilizar e o $\mathrm{R}$ Reciclar. No entanto, para o item $L$, podem configurar o desconhecimento parcial e/ou total sobre a temática.

Em suma, através da verificação das atitudes ambientais, do presente grupo de intervenção, é possível destacar aspectos que merecem apreensão, como o R - Reciclar e o R - Recusar, de forma a resultar em planejamentos didáticos nos momentos sequentes a essa atividade. Através da aplicação do Pentáculo Ambiental, verificouse ser necessário incentivar práticas de aproveitamento de materiais diversos como mecanismo de disseminação ecosustentável; explorar estratégias de equidade social e ecológica na produção de bens e serviços através da gestão ambiental; e fomentar a prática de EA na formação de valores em prol do meio ambiente.

\section{Discussão}

O processo educativo envolve uma série de abordagens cognitivas e afetivas. Para atingir um sistema de ensino integrador, a metodologia didática escolhida requer estratégias eficientes para a investigação e para a aplicação de um conteúdo formativo ao público-alvo selecionado, conforme os resultados observados com a investigação (COSTEL, 2015). Neste contexto, uma metodologia, como aqui apresentada - "Pentáculo Ambiental", pode ser considerada "agregadora" de métodos, de procedimentos e de comportamentos, por estar baseada em princípios pedagógicos substanciando por objetivos claros, como, por exemplo, neste trabalho, a promoção da Educação Ambiental (EA) e a verificação das atitudes ambientais dos estudantes.

Ações que priorizem a EA são comumente apresentadas no âmbito escolar (por exemplo, BONOTTO e SEMPREBONE, 2010; CAVALCANTI NETO e AMARAL, 2011; BRITES e CABRAL, 2012; DA MATTA OLIVEIRA et al., 2013). Porém, a sua aplicabilidade ou eficiência é geralmente avaliada de modo pontual, sem a investigação permanente das consequências destas no desenvolvimento de um ideário ecológico ao longo do tempo.

Neste sentido, Carnegie (2014) afirma que não é possível mudar algo que não se possa medir, e para saber se as melhorias estão atuando na direção certa e com o suporte de evidências, deve-se ter um critério para monitorar o êxito. Nesse sentido, o "Pentáculo Ambiental" se propõe a tal tarefa, buscando a identificação de padrões positivos e negativos em relação à EA, de acordo com a proposta dos $5 R^{\prime}$ s. Os dados obtidos pela resolução do pentagrama permitem validar ou pelo menos identificar as ações que repercutem para o desenvolvimento sustentável e aquelas que ainda necessitam de suporte teórico e prático para melhor desempenho.

Alguns pesquisadores também analisaram a eficá- 
cia de atividades de EA sobre o incremento de valores ambientais responsáveis, utilizando diferentes métodos (como FEHLBERG; HÖHER; FERRARO, 2014). Olson et al. (2015) desenvolveram um instrumento para levantamento da consciência sustentável dos estudantes, amplo e integrador dos aspectos afetivos, cognitivos das três dimensões para o desenvolvimento sustentável. Gavião e Lima (2015), por exemplo, apresentaram um modelo de indicador de sustentabilidade por modelagem Fuzzy (através do software MATLAB R 2013), para um diagnóstico do grau de maturidade do ensino da EA e com a possibilidade de utilização no âmbito escolar.

Caciuc (2014) verificou com base num questionário aplicado às crianças, o desenvolvimento de atitudes sobre o respeito à natureza e a identificação das diferenças que surgem ao nível da consciência ecológica entre o meio rural e urbano. Com isso, o autor apontou a necessidade de implementação destes temas em idades precoces para viabilizar a redução da crise ambiental.

Entretanto, os vários autores apontam nas pesquisas que os adolescentes têm menos interesse e preocupação sobre as questões ambientais, do que estudantes mais jovens ou mais velhos (KAPLAN e KAPLAN, 2002; NEGEV et al., 2008; UITTO e SALORANTA, 2010; LIEFÄNDER et al., 2013; LIEF ̈̈NDER e BOGNER, 2014; OLSSON e GERICKE, 2016). Dados estes, que podem corroborar a preferência pela escala 1 - "às vezes", nas respostas dos estudantes para as atitudes ecológicas referentes aos $5 R$ 's, ou o nível intermediário da maioria dos estudantes no somatório individual da escala de 0 a 3 .

É preciso ressaltar ainda que as respostas apresentadas pelo preenchimento do Pentáculo podem ser resultado das escolhas didáticas para abordagem dos temas associados. Quando incluídas em sala de aula, as práticas de EA de maior preferência pedagógica geralmente estão associadas à reutilização de materiais e a redução no consumo (CAMPOS e CASSAVAN, 2007; SANTOS et al., 2011), ou generalizadas como atividades de reciclagem (por exemplo, BASTIANELLO, 2005; ASSAD et al., 2011). O que ficou evidente nos dados, pela dependência das variáveis componentes do R - Reduzir, do R - Reutilizar e do R - Reciclar.

Já as questões de gestão ambiental e de implantação de sistema de gestão ambiental ainda são recentes e muitas vezes escassas, ou restritas às ações de formação docente (por exemplo, RODRIGUES et al., 2016), ou à critérios da administração escolar (por exemplo, MAGALHÃES, 2012), o que por sua vez, pode comprovar a dificuldade de compreensão das questões associadas ao $\mathrm{R}$ - Recusar (principalmente o item L) nas respostas dos estudantes desta pesquisa.

Quanto à integração dos apontamentos que compõem cada um dos eixos do pentagrama, observam-se as correlações positivas dos dados amostrados para o viés da sustentabilidade. Isso indica que, a construção de um sistema de valores e atitudes normativos para a sociedade definir relações harmônicas entre o homem e natureza, principalmente através dos $5 R^{\prime}$ s, pode representar um mecanismo para a cidadania ambiental. A realização deste intuito pressupõe o limite do consumo excessivo; a erradicação da pobreza; a sublimação das necessidades humanas, isto é, limitação do consumo de bens e serviços e o incentivo aos aspectos intelectuais (como a ciência e as artes). Além disso, implica também usar a criatividade para melhor eficiência na utilização dos recursos naturais permitindo a preservação da integridade, da beleza, da diversidade e da sustentabilidade de todos os ecossistemas do planeta Terra (NASIBULINA, 2015).

Para Berryman e Sauvé (2016), aspirar uma cidadania ambiental significa convidar todos para analisar as questões políticas, econômicas e sociais atuais à luz de maneiras possíveis de conceber e agir com prudência ecológica na nossa sociedade e na nossa vida em prol do desenvolvimento sustentável.

Para este efeito, a educação representa um dos fatores-chave, um processo que requer mais do que o ensino formal, mas sim, uma forma de criar condições de aprendizagem para a formação da cultura ecológica ao longo da vida. Um ensino que estimule a visão sistêmica de mundo, o pensamento crítico, um estilo de vida saudável, o cultivo de valores morais, o consumo sustentável e o ativismo social pacífico (NASIBULINA, 2015). No entanto, é verdade que a educação sozinha não pode resolver a totalidade de problemas do meio ambiente, mas pode amenizá-los através de uma educação ecológica, pois, é mais fácil e mais econômica a prevenção do que o reparo dos danos na natureza (CACIUC, 2014).

Nesta perspectiva, promover e apoiar atividades e comportamentos pró-ambiente entre crianças e jovens em geral pode constituir o indicador da sustentabilidade. Os atributos da sustentabilidade podem ser descritos em termos de conhecimentos, aptidões e competências que estão sustentados por propriedades afetivas, como valores e atitudes (SHEPHARD et al., 2015). Além disso, a educação na família é um importante passo para a defesa da EA (SABO, 2011).

Para isto, ações educativas, como o "Pentáculo Ambiental", podem ser usadas para orientar o desenvolvimento sustentável, seja na escola ou nas residências, de forma individual ou coletiva, mobilizando conhecimentos específicos para novas visões de mundo, e para novas formas verdes de produção e de consumo em consonância com a natureza.

\section{Conclusões}

Enfim, a discussão sobre sustentabilidade vai muito além do esboçado aqui. Desse modo, não se pretendeu esgotá-la, mas explicitar alguns pontos relevantes para reflexão, assim como, o potencial de um mecanismo de verificação de atitudes ambientais para promoção da educação ambiental. Além disso, acenar para alguns problemas que precisam ser enfrentados e que possibili- 
tam a discussão em torno do processo desenvolvimento sustentável.

\section{Referências}

ASSAD, L. G., BERARDINELLI, L. M. M., DA SILVA, D. P. P., DE OLIVEIRA JUNIOR, A. A. B.; RODRIGUES, T. G. Reciclagem de papel: uma experiência de ensino, extensão e pesquisa. Interagir: pensando a extensão. 2011, 16: 53-57.

BARBETTA, P. A. Estatística Aplicada às Ciências Sociais. 9ª . ed. Florianópolis: Editora da UFSC; 2014.

BASTIANELLO, S. F. Desenvolvimento de embalagens a partir de papel reciclado reforçado com fibras naturais: uma proposta ambientalmente amigável. [Dissertação]. Universidade da Região de Joinville, Santa Catarina; 2005.

BERRYMAN, T.; SAUVÉ, L. Ruling relationships in sustainable development and education for sustainable development. The Journal of Environmental Education. 2016, 47(2): 104-117.

BRITES, A. S.; CABRAL, I. E. Educação ambiental no contexto do Ensino de Ciências: um estudo de revisão. Ensino, Saúde e Ambiente. 2012, 5(2): 198-210.

BONOTTO, D. M. B.; SEMPREBONE, A. Educação ambiental e educação em valores em livros didáticos de ciências naturais. Ciência \& Educação (Bauru). 2010, 16(1): 131-148.

CACIUC, V. T. Ecocentric Reflections on the Realization of Environmental Education. Procedia-Social and Behavioral Sciences. 2014, 137: 93-99.

CAMPOS, S. S. P.; CAVASSAN, O. A oficina de materiais recicláveis no ensino de ciências e nos programas de educação ambiental: refletindo sobre a prática educativa. In: Anais do VI Encontro Nacional de Pesquisa em Educação em Ciências (ENPEC); 2007 Nov-Dez 2701; Florianópolis, Brasil. 2007 [cited 2016 Abr 15]. Disponível a partir: http://www.fae.ufmg.br/abrapec/ viempec/viempec/entrar.html.

CARVALHO, I. C. M. Educação ambiental: a formação do sujeito ecológico / Isabel Cristina de Moura Carvalho, 6 ${ }^{\mathrm{a}}$. ed., São Paulo: Cortez, 2012.

CARNEGIE (Foundation for the Advancement of Teaching). 2014. Community Engagement Classification. Accessed September 25, 2014. Disponível a partir: http:// classifications.carnegiefoundation.org/descriptions/ community_engagement.php.
CAVALCANTI NETO, A. L. G.; AMARAL, E. M. R. Análise de concepções e visões de professores de ciências sobre educação ambiental. Pesquisa em Educação Ambiental. 2011, 6(2): 119-136.

CHAWLA, L.; CUSHING, D. F. Education for strategic environmental behavior. Environmental Education Research. 2007, 13: 437-452.

COSTEL, E. M. Didatics options for the environmental education. Procedia - Social and Behavioral Sciences. 2015, 180: 1380-1385.

DA MATTA OLIVEIRA, N., REIS, M., DO VALLE PERLINGEIRO, R., FRAZÃO, A. C., CLAUSSEN, K.; GALIETA, T. Imagens de Educação Ambiental de futuros professores de Ciências Biológicas. Revista Práxis. 2013, 5(9): 57-63.

DA SILVA, P.; BASTOS, C. Desenvolvimento Sustentável: uma abordagem em construção no transporte público. InterfacEHS-Revista de Saúde, Meio Ambiente e Sustentabilidade. 2007, 2(4): 1-8.

FEHLBERG, E. B.; HÖHER, B. G.; FERRARO, C.S. Educação Ambiental: Um processo coletivo para estimular habilidades, competências e valores sociais por meio de uma Unidade de Aprendizagem. In: $4^{\circ}$ Congresso Internacional de Tecnologias para o Meio Ambiente; 2014 Abr 23-25; Bento Gonçalves, Brasil. 2014. [cited 2016 Abr 15]. Disponível a partir: http://vbaco01.ucs.br/ congressoAnais2014/getArtigo. php?id=452.

GAVIAO, L. O.; LIMA, G. B. A. Indicadores de sustentabilidade para a educação básica por modelagem fuzzy. Revista Eletrônica em Gestão, Educação e Tecnologia Ambiental. 2015, 3(19): 274-297.

GOVERNO A política dos 5 R's. 2016. Disponível a partir: http://www.mma.gov.br/comunicacao/item/9410a-pol\%C3\%ADtica-dos-5-r-s.

KAPLAN, R.; KAPLAN, S. Adolescents and the natural environment: A time out. In P. H Kahn \& S. R. Kellert (Eds.), Children and nature. Psychological, sociocultural, and evolutionary investigations. Boston, MA: MIT press. 2002: 227-257.

KOPNINA, H. Education for sustainable development (ESD): the turn away from 'environment' in environmental education?, Environmental Education Research. 2012, 18(5): 699-717.

LIEFLÄNDER, A. K.; BOGNER, F. X. The effects of children's age and sex on acquiring pro-environmental attitudes through environmental education. The Journal of Environmental Education. 2014, 45(2): 105-117. 
LIEFLÄNDER, A. K.; FRÖHLICH, G.; BOGNER, F. X.; SCHULTZ, P. W. Promoting connectedness with nature through environmental education. Environmental Education Research. 2013, 19(3): 370-384.

LOPES RG, DE MOURA LR. Responsabilidade socioambiental: uma análise do projeto "campus verdegestão ambiental do IFRN". HOLOS. 2015, 3(24): 135-47.

MAGALHÃES, H. G. O conceito de gestão escolar na ecopedagogia. REMEA-Revista Eletrônica do Mestrado de Educação Ambiental. 2012, 9(17): 262-273.

MORETTIN, P. A.; BUSSAB, W. O. Estatística Básica. 6a . ed. São Paulo: Saraiva; 2010.

NAHAS, M. V. Atividade Física, Saúde e Qualidade de Vida. 6a. ed. Londrina: Midiograf, 2013.

NASIBULINA, A. Education for Sustainable Development and Environmental Ethics. Procedia - Social and Behavioral Sciences. 2015, 214: 1077-1082.

NEGEV, M.; SAGY, G.; GARB, Y.; SALZBERG, A.; TAL, A. Evaluating the environmental literacy of Israeli elementary and high school students. The Journal of Environmental Education. 2008, 39(2): 3-20.

OLSSON, D.; GERICKE, N. The adolescent dip in students' sustainability consciousness - Implications for education for sustainable development. The Journal of Environmental Education. 2016, 1(47): 35-51.

OLSSON, D.; GERICKE, N.; CHANG-RUNDGREN, S-N. The effect of implementation of education for sustainable development in Swedish compulsory schools - assessing pupils' sustainability consciousness. Environmental Education Research. 2015, 47(1): 35-51.

POSTEUCĂ, N. L. Organizational culture and Entreprenorial Performance in Business Administration. Philosophy, Social and Human Disciplines, 1, Stefan cel Mare University of Suceava. 2013: 69-77.

RAMOS, T. B.; CAEIRO, S.; HOFF, B. V.; LOZANO, R.; HUISINGH, D.; CEULEMANS, K. Experiences from the implementation of sustainable development in higher education institutions: Environmental Management for Sustainable Universities. Journal of Cleaner Production. 2015, 106: 3-10.

RODRIGUES, A. M.; DE MENEZES, J. B. F.; DE ARAUJO RODRIGUES, M. V.; DE ABREU, M. K. F. Gestão Ambiental na Educação Básica: A realidade de escolas da rede estadual de ensino em Iguatu, Ceará, Brasil. Revista Eletrônica em Gestão, Educação e Tecnologia Ambiental. 2016, 20(1): 40-49.
$\mathrm{SABO}, \mathrm{H}$. M. Environmental education and sustainable development general aspects. International Conference on Social Science and Humanity IPEDR, 5, IACSIT Press, Singapore. 2012, 2: 2-8.

SANTOS, A. F. Como transformar e criar artes na escola através de resíduos sólidos [manuscrito]/ Adriana Ferreira dos Santos. 2015.

SANTOS, P. T. A., DIAS, J., LIMA, V. E., OLIVEIRA, M. J., NETO, L. J. A., \& CELESTINO, V. Q. Lixo e reciclagem como tema motivador no Ensino de Química. Eclética Química. 2011, 36(1): 78-92.

SHEPHARD, K.; HARRAWAY, J.; LOVELOCK, B.; MIROSA, M.; SKEAFF, S.; SLOOTEN, L.; STRACK, M.; FURNARI, M.; JOWETT, T.; DEAKER, L.. Seeking learning outcomes appropriate for 'education for sustainable development' and for higher education. Assessment \& Evaluation in Higher Education. 2015, 40(6): 855-866.

SIMONNEAUX, J.; SIMONNEAUX, L. Educacionais para o ensino de questões sociocientíficos ambientais dentro da perspectiva da sustentabilidade. Investigação em Ciências da Educação. 2012, 42(1): 75-94.

SMANEOTO, C.; CENCI, D. R.; DE LIMA, J. M. A Educação Ambiental como direito fundamental do homem. Revista Monografias Ambientais. 2012, 5(5): 922-933.

STONE, M. K.; BARLOW, Z.; CAPRA, F. “Alfabetização Ecológica: a educação das crianças para um mundo sustentável." In: Alfabetização ecológica: a educação das crianças para um mundo sustentável. Cultrix; 2006.

TORRES, J. R; FERRARI, N.; MAESTRELLI, S. R. P. Educação ambiental crítico-transformadora no contexto escolar: teoria e prática freireana. In: Educação Ambiental: dialogando com Paulo Freire/ Carlos Frederico Bernardo Loureiro, Juliana Rezende Torres, (orgs.). 1. ed. São Paulo: Cortez, 2014. p.13-80.

UITTO, A.; SALORANTA, S. The relationship between secondary school students' environmental and human values, attitudes, interests and motivations. Procedia Social and Behavioral Sciences. 2010, 9(0): 1866-1872.

VICENTE, A. N. da C; PICOLO, A. F. O.; GOMES; C. M.; VIEBIG, R. F. Aplicabilidade do Pentáculo do Bemestar como ferramenta para nutricionistas. Revista Digital, Buenos Aires. 2009, 13(129). 